\title{
O lugar da experiência no âmbito da Educação Física
}

\author{
Luciano de Almeida* \\ Paulo Evaldo Fensterseifer ${ }^{* *}$
}

\begin{abstract}
Resumo: o presente artigo traz para a discussão o lugar da experiência e do saber da experiência como possibilidade de conhecer no âmbito das práticas corporais na Educação Física. Para isso, recorre à hermenêutica filosófica de Hans-Georg Gadamer para compreender o movimento da Educação Física em legitimar-se em distintos espaços sociais, situando-a no tempo, contextualizando sua tradição e os desdobramentos desta para a produção do conhecimento. Compreender a experiência pode nos possibilitar as chaves para a compreensão do fenômeno complexo do movimento humano, já que esta não pode ser entendida como manipulação e controle, mas sim como participação e abertura.
\end{abstract}

Palavras chave: Experiência, Educação Física, Hermenêutica

A Educação Física, durante sua constituição enquanto área do conhecimento, privilegiou a vivência de movimentos ou práticas corporais no plano de atividades. A crítica a essa tradição, porém, enfatizou a necessidade de uma elaboração conceitual acerca das vivências de movimento, o que nos coloca em risco de promovermos uma inversão, valorando o lado conceitual em detrimento das vivências. Mas, feito esse movimento, resta-nos perguntar: qual o lugar da experiência e do saber da experiência como possibilidade de conhecer no âmbito das práticas corporais, neste novo estágio da área?

Antes de tentarmos esboçar um entendimento sobre essa questão, acreditamos ser necessário, mesmo que em breves palavras,

\footnotetext{
"Professor de Educação Física do Instituto Federal de Educação, Ciência e Tecnologia Farroupilha -Campus Santo Augusto/RS. E-mail: lucianoedf@sa.iffarroupilha.edu.br

"Professor do Departamento de Pedagogia Unijuí/RS. E-mail: fenster@unijui.edu.br
} 
situar a Educação Física no tempo, por entendermos que nossa compreensão está situada à luz do presente e da historicidade que nos constitui. No entanto, não há como sairmos do mundo para compreendê-lo e, no momento em que interpretamos algo, o fazemos a partir do encontro com a tradição da qual nós mesmos procedemos, pois o fato de estarmos na tradição não restringe a nossa liberdade de conhecer, "antes é o que a torna possível" (GADAMER, 2008, p. 471).

Nesse sentido, compreendemos a Educação Física pela relação de tensão permanente que há entre o passado e o presente desta área do conhecimento. Durante sua constituição vinculou-se a outras áreas do conhecimento para afirmar sua cientificidade, na tentativa de justificar-se em diferentes espaços sociais. Devido à importância dada a esta nos diferentes momentos históricos, associou-se a diferentes instituições que conduziram suas "práticas" de acordo com seus respectivos interesses. Podemos citar, entre elas, a instituição militar e a instituição esportiva. A primeira, com a intenção de fortalecer física e moralmente os sujeitos ("manutenção da ordem"); a segunda, ressaltando a importância da aptidão física através do esporte ("formação de atletas") (BRACHT, 1992).

Percebemos, nessas breves palavras, o caráter instrumental da Educação Física, que por um longo período esteve subordinada aos códigos e normas dessas instituições. Surge, enfim, na década de 80, o que se convencionou chamar de "Movimento Renovador da Educação Física" na tentativa de atribuir novos rumos a esta área do saber. Ela passa a ser discutida sob a influência das teorias críticas da educação, questionando-se sobre o seu lugar no interior da escola e sua relação com as questões do universo político mais amplo. Cabe ressaltar, porém, que esse movimento restringiu-se quase que exclusivamente às discussões no meio acadêmico, com um caráter de denúncia, sem uma ênfase maior em iniciativas propositivas (voltadas à intervenção).

Essas iniciativas ocorrem, com maior destaque, a partir da década de 90, com a intencionalidade de tentar romper com o dualismo teoria/prática, residente na área. Cabe destacar que essas 
propostas tentaram dar um novo sentido à Educação Física, sem ignorar o vínculo histórico-político-social e cultural de uma área de conhecimento e intervenção pedagógica (BETTI, 2005), e a consequente tentativa de sistematização dos temas/conteúdos que foram incorporados como específicos desta disciplina e sua relação com o específico da educação escolar. Em sua história atendeu diferentes objetivos: saúde, aptidão física, rendimento, desenvolvimento motor, etc., todos relacionados em indicadores físicos e vinculados a uma "matriz científica" (BETTI, 1996).

É a partir dessa tradição, atravessando o tempo e sendo constituídos por essas influências, que interpretamos/compreendemos a Educação Física. Cabe destacar que cada época compreende ao seu modo um texto ou conteúdo transmitido, pois o texto ou conteúdo "forma parte do todo da tradição na qual cada época tem um interesse objetivo e onde também ela procura compreender a si mesma" (GADAMER, 2008, p. 392). Recorremos à hermenêutica para que nos auxilie a interpretar e compreender esse movimento de legitimação em diferentes espaços, em especial, no âmbito escolar. Ensina-nos a hermenêutica que não há como interpretar/compreender algo fora do tempo, do pertencimento a um momento histórico. É a partir de determinado horizonte que compreendemos. Horizonte, que para Gadamer (2008, p. 399), "é o âmbito de visão que abarca e encerra tudo o que pode ser visto a partir de um determinado ponto". Compreender é estar em relação, a um só tempo, "com a coisa mesma que se manifesta através da tradição e com uma tradição de onde a 'coisa' possa me falar" (GADAMER, 2006, p. 67).

O que nos fala a Educação Física, no presente, sob o viés de uma tradição que nos colocou "pretensões de maioridade"? Utilizandose da expressão tomada de Ernildo Stein "entre o não mais e o ainda não", Fensterseifer e González (2007) afirmam que a Educação Física está entre uma prática em que não se acredita mais e uma outra que se tem dificuldades de pensar.

Cabe a nós, a partir da nossa capacidade de "reaprender a ver o mundo [Educação Física]", buscarmos então um entendimento ou uma redefinição das especificidades deste componente curricular 
"no mundo", na produção do conhecimento e nas práticas pedagógicas (FENSTERSEIFER, 2006). Esse entendimento encontra uma possibilidade de interpretação na afirmação de que qualquer posição "nova", com a pretensão de substituir uma outra, "segue necessitando da 'antiga', já que ela não pode se explicitar enquanto não souber a que nem por que ela se opõe" (GADAMER, 2006, p. 69).

Podemos nos perguntar então: a que e por que nos opomos a "certa" tradição da Educação Física e vislumbramos a possibilidade de manifestar uma "nova" posição para ela? Nos últimos anos fomos convocados a repensá-la para além de uma atividade, de um "fazer pelo fazer", em especial, após o movimento renovador da Educação Física, que buscou contribuir para a legitimação desta "disciplina", pensando no "objeto" e na definição da especificidade desta área do conhecimento e de um "saber" específico de que trata essa prática pedagógica. De acordo com Bracht (2003, p. 42), é preciso pensar o seu objeto como um saber específico, numa tarefa pedagógica específica, "cuja transmissão/tematização e/ou realização seria atribuição desse espaço pedagógico que chamamos EF". Ao ser pensada como uma prática pedagógica, pode nos dar indicativos para auxiliar a superar a "crise de identidade" da área, pois ela não pode ser considerada uma disciplina científica, nem tampouco, uma disciplina com estatuto epistemológico próprio (BRACHT, 2003), posto que a falta de um estatuto próprio de ciência nos fez "moradores de fronteiras"1 (FENSTERSEIFER, 2006).

Morar nessas fronteiras, não é exclusividade nossa, "outras disciplinas" também vivem um dilema semelhante, como é o caso da literatura, que não é um conhecimento conceitual, como afirma Palmer (1989), mas, experiência ${ }^{2}$. A experiência sempre acontece em perspectiva própria e é aqui entendida como algo que se deve

\footnotetext{
'Segundo Fensterseifer (2006) habitamos um "território de fronteiras" ou somos "moradores de fronteiras", pois nos apropriamos de diferentes "ciências" para nos justificar enquanto "disciplina" no âmbito escolar.

${ }^{2}$ Porém é necessário perceber que embora não sendo um conhecimento conceitual, permite que sobre ela se elabore um conhecimento conceitual atingindo um dos propósitos da educação escolar.
} 
"provar" (no sentido de experienciar), através da relação com algo que se quer compreender, e não como algo que se deva "explicar" para o outro, no sentido de simples descrição.

Se entendermos a experiência como descrição, estaremos elaborando um tipo de conhecimento puramente técnico para se chegar a um determinado produto, "um conhecimento, portanto, que se adquire antes do ato produtivo" (FLICKINGER, 2010, p. 119). Essa é a pretensão de uma racionalidade técnica que não abre espaço para o inesperado e busca verdades absolutas, como afirma Larrosa (2002, p. 28), que não podemos antecipar um resultado, a experiência é uma "abertura para o desconhecido, para o que não se pode antecipar nem 'pré-ver' nem 'pré-dizer'". Ao aproximarmos o processo pedagógico aos ditames da cientificização em suas pretensões de controle e manipulação das circunstâncias em que tal processo ocorre (HERMANN, 2002), corremos o risco de "objetificar" a experiência produzindo um saber discursivo meramente instrumental, "já que no processo de sua aplicação não se reflete absolutamente acerca da postura dos indivíduos nele envolvidos" (FLICKINGER, 2010, p. 119). Essa afirmação vem ao encontro do alerta de Betti (1994) de que a Educação Física não deve se tornar um discurso sobre a cultura corporal de movimento, ou, de acordo com Bracht (2003), não podemos transformá-la num discurso sobre o movimento.

O discurso sobre a cultura corporal de movimento e/ou sobre o movimento se dá no plano conceitual, que não nos permite uma interpretação a partir da experiência, das vivências de movimento/ práticas corporais, mas pela sua descrição. Não estamos, porém, negando a dimensão conceitual que se articula com as dimensões procedimentais e atitudinais, mas realçando a valorização da experiência e do saber da experiência como possibilidade de conhecer, fazer e conhecer com esse fazer. Compreender o saber da experiência pode nos possibilitar as chaves para a compreensão do fenômeno complexo da experiência do movimento humano na Educação Física, já que esta não pode ser entendida como "lócus" 
de manipulação e controle, mas como espaço de participação e abertura: "não é o conhecimento mas sim a experiência, não é a metodologia mas sim a dialéctica" (PALMER, 1989, p. 216).

A não incorporação de pressupostos teóricos em nossas ações pode ser um indicativo de que um conhecimento conceitual nos limitaria a não experimentarmos as coisas (o que é específico da $\mathrm{EF}$ ) e, assim, se entendermos a experiência como algo que se passa e que acontece, e não como algo que nos acontece e nos toca, poderia nos constituir em sujeitos informados, mas sem nos entregarmos à experiência (LARROSA, 2002).

Tal afirmação pode nos auxiliar a refletir sobre os desdobramentos que a experiência e o saber da experiência podem provocar durante nossa constituição enquanto sujeitos da experiência. Somos um "território de passagem" do que nos acontece (LARROSA, 2002), porém essa "passagem" não está isenta de atingir um nível de consciência do que nos acontece nesta experiência finita. Esses desdobramentos nos convocam a pensar sobre as contribuições da noção de experiência para a compreensão da prática pedagógica, da formação discente e docente, da construção do conhecimento e da construção de um currículo mínimo para a Educação Física.

Acreditamos que a experiência da filosofia, da arte e da própria história pode contribuir para a compreensão da experiência do movimento humano na Educação Física, mesmo que esta, tradicionalmente, esteja associada às ciências da natureza tentando justificar-se em distintos espaços sociais de maneira objetificada e metódica, característica das ciências modernas ${ }^{3}$. O propósito do fenômeno da compreensão é "rastrear por toda parte a experiência da verdade, que ultrapassa o campo de controle da metodologia científica" e, ainda, "indagar por sua própria legitimação onde quer que se encontre" (GADAMER, 2008, p. 29-30). É assim que acabam confluindo as ciências do espírito com as formas de experiência que

\footnotetext{
${ }^{3}$ Não estamos negando com isso o vínculo existente entre o movimento humano e as ciências da natureza como forma de conhecimento na Educação Física. Estamos sim trazendo para a discussão as limitações de pensar a experiência do movimento humano sob essa ótica, tentando eliminar o sujeito histórico da própria experiência.
} 
se situam fora do âmbito da ciência, como é o caso da experiência da filosofia, da arte e da própria história. Esses são modos de experiência "nos quais se manifesta uma verdade que não pode ser verificada com os meios metodológicos da ciência" (idem).

Nesse sentido, buscamos compreender a experiência do semovimentar como possibilidade de conhecer no âmbito das práticas corporais na Educação Física. Optamos pela expressão semovimentar por ter um caráter mais vivencial do que movimento humano, tendo em vista que esta última está mais associada aos meios metódicos da ciência na forma de análise do movimento humano, como, por exemplo, a interpretação/compreensão do movimento humano no esporte pela biomecânica (KUNZ, 2001).

Primeiramente, faz-se necessário atribuirmos sentido ao que estamos entendendo por experiência. Em um primeiro plano, encontramos, na obra de Gadamer (2008, p. 453), uma análise da estrutura da experiência que permite olharmos para a experiência como "um dos conceitos menos elucidados que temos", por mais paradoxal que possa parecer. Para o autor, o conceito de experiência viu-se submetido a uma esquematização epistemológica que mutila seu conteúdo originário, em especial por tentar "anular" qualquer elemento histórico que há na experiência.

A experiência assume um caráter de experimento, tanto nas ciências da natureza, através de seu aparato metodológico, quanto nas ciências do espírito, pelo método da crítica histórica, em que a objetividade é garantida "pelo fato de as experiências feitas ali poderem ser repetidas por qualquer pessoa" (GADAMER, 2008, p. 454). Enquanto, na primeira, "os experimentos devem ser passíveis de verificação", na segunda, "o procedimento completo deve ser passível de controle" (GADAMER, 2008). Nesse sentido, na ciência "não pode restar espaço para a historicidade da experiência" (GADAMER, 2008).

O aspecto "experimental" da experiência, no âmbito da ciência moderna, portanto, deixa pouco espaço para a experiência, justamente pelo fato de tentar excluir o elemento histórico da própria experiência. 
Na tentativa de compreender a experiência e o saber da experiência do movimento/práticas corporais na Educação Física, vamos fazer um contraponto entre ciência moderna e hermenêutica.

Na perspectiva da ciência moderna (objetivista), a experiência do movimento/práticas corporais na Educação Física assumiria um caráter laboratorial, em que há pouca experiência nas experiências, numa relação de sujeito-objeto relacionada com o método e o experimento, na tentativa de torná-la tão objetiva "a ponto de anular nela qualquer elemento histórico" (GADAMER, 2008, p. 454). Numa perspectiva hermenêutica, porém, a experiência do movimento/ práticas corporais aconteceria em caráter existencial, do que nos acontece, nos toca, nos transforma, nos faz ver as coisas de uma maneira especial e sempre singular, pois a experiência é "algo que acontece aos seres humanos possuidores de vida e de história... contradiz as expectativas, e assim é o maior dos mestres, para o qual não há substituto" (PALMER, 1989, p. 233).

Reafirmamos que a experiência sempre acontece em perspectiva própria e "só se atualiza nas observações individuais. Não se pode conhecê-la numa universalidade prévia" (GADAMER, 2008, p. 460). Essa afirmação fica ainda mais evidente quando tratamos do movimento/práticas corporais como objeto da experiência na Educação Física. "Conhecer" determinado movimento/prática corporal no plano conceitual, em uma universalidade prévia, restringe nossa possibilidade de "fazermos" uma experiência, pois, de acordo com Gadamer (2008), quando fazemos uma experiência com um objeto "significa que até então não havíamos visto corretamente as coisas e que só agora nos damos conta de como realmente são" (GADAMER, 2008, p. 462).

Fazer uma experiência deve nos proporcionar "um saber melhor, não somente sobre si mesmo mas também sobre aquilo que antes se acreditava saber, isto é, sobre o universal" (GADAMER, 2008). Para tanto, implica um esforço de ter de se confirmar constantemente e converter-se em uma nova experiência, já que não se pode fazer essa experiência confirmada e repetida novamente. "Quando se fez uma experiência, isso significa que a possuímos" (GADAMER, 2008), 
tornamo-nos uma pessoa experimentada. Ser "experimentado", segundo Gadamer (2008, p. 465), é estar aberto a novas experiências, pois o

homem experimentado evita sempre e de modo absoluto o dogmatismo, e precisamente por ter feito tantas experiências e aprendido graças a tanta experiência está particularmente capacitado para voltar a fazer experiências e delas aprender. A dialética da experiência tem sua própria consumação não num saber concludente, mas nessa abertura à experiência que é posta em funcionamento pela própria experiência.

Vejamos como a noção de experiência pode nos auxiliar a compreender os desdobramentos de nossa própria constituição a partir de nossas experiências enquanto alunos nas aulas de Educação Física, em nossas escolhas pelo curso, nas mudanças de sentido atribuídas a algo durante nossa graduação, nos enfrentamentos diários com nossos alunos, nas dificuldades de sustentar e justificar diferentes vivências/práticas corporais em nossas aulas... dentre outras questões, que fazem parte de nossa experiência formativa.

No transcorrer do tempo, seja num curto ou longo espaço temporal, podemos perceber que as mudanças de sentido vão acontecendo no momento em que nossas experiências começam a nos afetar de tal modo, a produzir afetos, nos deixar marcas, deixar alguns vestígios, alguns efeitos (LARROSA, 2002). Afinal, como afirma Gadamer (2006, p. 14), toda experiência é confronto, "já que ela opõe o novo ao antigo, e, em princípio, nunca sabe se o novo prevalecerá, quer dizer, tornar-se-á verdadeiramente uma experiência, ou se o antigo, costumeiro e previsível reconquistará finalmente a sua consistência" (p. 14).

Para exemplificar essa afirmação, recorremos a uma breve contextualização desse "confronto", das mudanças de sentido, durante nossa constituição pessoal/profissional, fazendo um recorte de um tema/conteúdo em especial, quase hegemônico nas aulas de Educação Física, o esporte. 
Na tradição da Educação Física, podemos dizer que o esporte conduziu/conduz as aulas de tal forma que se confunde com a própria área do conhecimento. Inseridos nessa tradição, fizemos uma opção pelo curso por ter uma relação de afinidade com o tema em questão, especialmente pelas vivências/práticas corporais (esportivas), enquanto alunos do ensino fundamental e médio e, ainda, nos espaços extracurriculares. Durante o processo de formação enquanto alunos do ensino superior, vamos participando de um processo de desvelamento da Educação Física, atribuindo novos sentidos a esta área de conhecimento, identificando as possíveis contribuições desse componente curricular na instituição escolar.

A oposição a essa tradição (esportiva) diz respeito à prática hegemônica de uma monocultura de esporte e não ao esporte. Fazemos essa leitura no atual momento de nossa compreensão, que se consolida a partir de um processo de permanente discussão no interior da área, em busca de uma "nova"4 concepção que nos auxilie a ampliar e justificar nossas ações pedagógicas, para além do plano de atividades esportivas.

Como pensar em oposição a uma tradição esportiva no momento em que vivenciávamos (enquanto alunos) o esporte na escola, em que proporcionava-nos um prazer imediato? Outra questão que surge a partir desta diz respeito a como nossos alunos vão se opor a uma tradição esportiva se não experimentarem "coisas novas" ${ }^{\text {, }}$, no sentido de provar, se entregar, se submeter a algo novo? Aprender exige esforço, pode não proporcionar um prazer imediato aos alunos, mas auxilia os mesmos a dar um novo sentido às vivências/práticas corporais nas aulas de Educação Física a partir da experiência com algo novo. Esse aprender também exige esforço nosso, enquanto docentes, de nos entregarmos a algo novo, para que uma nova experiência nos interpele. Nessa perspectiva de entregar-se a uma nova situação, aceitando o risco das incertezas que a experiência

\footnotetext{
${ }^{4}$ Essa nova concepção de Educação Física refere-se ao confronto que a experiência proporciona entre o novo e o antigo (tradição) (GADAMER, 2006).

${ }^{5}$ Expressão utilizada por um aluno em uma avaliação no final do ano, após a ampliação do tema/ conteúdo esporte nas aulas de Educação Física em 2007.
} 
proporciona, podemos dar um novo "rumo" ao processo educativo extrapolando a relação sujeito-objeto, no sentido do sujeito que domina o objeto e que costuma reduzir o espaço da experiência (HERMANN, 2002).

Tanto o aprender discente quanto o aprender docente nos convocam a pensar a experiência como experiência e não como experimento. Como experimento, temos a pretensão de controlar e manipular as coisas e não abrimos espaço para as incertezas e contradições das relações humanas que a experiência nos proporciona, desde que nos entreguemos e nos submetamos a ela. Afinal, no acordo com Gadamer (2008, p. 462), a verdadeira experiência é sempre negativa ${ }^{6}$, possui um sentido marcadamente produtivo e não pode ser considerado um engano "que é visto e corrigido, mas representa a aquisição de um saber mais amplo".

Esse entregar-se à experiência é um estar aberto a novas experiências, muito difícil nos tempos que correm, quase impossível sem um gesto de interrupção, pois é preciso parar

para pensar, parar para olhar, parar para escutar, pensar mais devagar, olhar mais devagar, e escutar mais devagar; parar para sentir, sentir mais devagar, demorar-se nos detalhes, suspender a opinião, suspender o juízo, suspender a vontade, suspender o automatismo da ação, cultivar a atenção e a delicadeza, abrir os olhos e os ouvidos, falar sobre o que nos acontece, aprender a lentidão, escutar aos outros, cultivar a arte do encontro, calar muito, ter paciência e dar-se tempo e espaço (LARROSA, 2002, p. 24).

Enquanto estivermos pensando a experiência como algo negativo, em que nossas expectativas não são atendidas, continuaremos a tentativa de nos poupar ou de poupar nossos alunos da própria experiência. A experiência não é algo que possa ser poupado a alguém, como fazem alguns pais para poupar seus filhos

\footnotetext{
${ }^{6}$ Essa negatividade, segundo Gadamer (2008), reside no fato de considerar o resultado da experiência por universalizações típicas em que nossas expectativas são atendidas, e não como uma experiência que se "faz", em que nos possibilita ver as coisas como realmente são e não como acreditávamos saber.
} 
de certas experiências dolorosas e desagradáveis. Ela faz parte da essência do homem e "pressupõe necessariamente que se frustrem muitas expectativas, pois somente é adquirida através disso" (GADAMER, 2008, p. 465).

Encontramos alento nas palavras de Gadamer (2008) ao pensarmos em nossa intervenção profissional em que nossas expectativas não são atendidas. De acordo com o autor, a experiência acontece em um duplo sentido: a experiência que atende nossas expectativas e as confirma (o que poderíamos chamar de experimento) e a experiência que realmente se "faz"; esta, a verdadeira experiência, demonstra um caráter de imprevisibilidade, pois nos expõe aos riscos e incertezas que a tarefa educativa proporciona.

Na tentativa de exemplificar a afirmação do autor, estabelecemos uma relação comparativa entre "experimento" e "experiência" no âmbito do movimento/práticas corporais na Educação Física, trazendo elementos de nossa própria intervenção profissional ${ }^{7}$. Um primeiro exemplo diz respeito a uma "experiência" com o ensino do handebol. A aula foi planejada com base em uma forma "tradicional" e/ou disciplinar de ensino (proposta em partes), composta apenas de elementos técnicos, sem uma preocupação maior com o sujeito da experiência. Os alunos realizaram todas as atividades propostas e a aula transcorreu dentro da normalidade em que nossas expectativas foram atendidas, pois os objetivos estavam focados no resultado final, de cumprir com o proposto (adequar o tempo e realizar as atividades). Podemos dizer que presenciamos, neste caso, o experimento do movimento; uma aula que poderia ser repetida sem considerar o elemento histórico da própria experiência (racionalidade técnica-instrumental); um espaço fechado de realização de atividades, sem lugar para o diálogo, pautado nos movimentos "já realizados por terceiros" e não no Ser Humano que se movimenta (KUNZ, 2005).

\footnotetext{
${ }^{7}$ Tomamos como exemplo, a experiência de um dos autores, em duas aulas de Educação Física, com a mesma turma, porém com abordagens de ensino diferentes, em uma escola pública estadual no ano de 2007.
} 
Um segundo exemplo diz respeito a uma experiência com o ensino do atletismo. A aula foi planejada com base na concepção de aulas abertas às experiências subjetivas ${ }^{8}$ com o tema "corrida com obstáculos", tendo sido realizada no bosque ao lado da escola. A turma foi dividida em grupos e cada grupo deveria estruturar um espaço de corrida e de salto com os materiais disponíveis no bosque e experimentá-lo. Após a experimentação nos grupos, estruturamos uma única pista com cada "estação" criada pelos grupos e novamente houve uma experimentação, agora de forma coletiva. Percebemos nesta aula como os alunos tentaram resolver em seus grupos a construção da pista de obstáculos; como cada aluno, a seu modo, resolvia o problema de superar o obstáculo: por exemplo, alguns imprimiam maior velocidade, outros tomavam uma distância maior, adotando um estilo próprio de saltar sem a utilização de uma técnica pré-definida. É importante salientar também o espaço do diálogo entre alunos-alunos e alunos-professor, ajudando-se mutuamente, para que transcendessem seus próprios limites (KUNZ, 2001). Considerando o segundo exemplo, podemos afirmar que o sujeito histórico da experiência foi considerado. Nesta perspectiva, o movimento humano "consiste de experiências significativas e individuais, onde pelo seu Se-movimentar o Indivíduo realiza sempre um contato e um confronto com o Mundo material e social, bem como consigo mesmo" (KUNZ, 2001, p. 165).

Ao aproximarmos a tarefa educativa deste segundo exemplo de experiência, estabelecemos uma nova relação com o processo pedagógico, não mais baseada na simples transmissão de conhecimentos, mas na possibilidade de promover

a oportunidade de o educando e o educador entregarem-se a uma situação aberta, a um diálogo que, além de trabalhar determinados conteúdos, se processa como relação social; ou seja, como relação

${ }^{8}$ Destacamos o professor Reiner Hildebrandt-Stramann (2001), que entende as situações abertas de ensino nas aulas de Educação Física como um espaço de experimentação do movimento humano através da resolução de um problema e de uma intencionalidade e não uma cópia de movimentos padronizados. 
de desafio, no sentido de fazer do vir ao encontro do outro o campo de aprendizagem intersubjetivo e, por isso mesmo, ético-moral (FLICKINGER, 2010, p. 6-7).

Sem a pretensão de ter alcançado um saber concludente, percebemos que a experiência e o saber da experiência ocupam um lugar fundamental no âmbito das práticas corporais na Educação Física, "para o qual não há substituto". Conhecer, no âmbito das práticas corporais, requer um entregar-se à experiência. Temos receio e medo de fazer "certas" experiências de movimento/práticas corporais por não conseguir controlá-las, e muitas vezes optamos por fazer "experimentos". O processo educativo enquanto experiência hermenêutica, porém, "exige a exposição ao risco, às situações abertas e inesperadas, coincidindo com a impossibilidade de assegurar a tais práticas educativas uma estrutura estável, que garanta o êxito da ação interventiva" (HERMANN, 2002, p. 86). Nesse experimentar não negamos o saber conceitual, pois no momento em que tematizamos determinadas práticas corporais elaboramos um saber conceitual para atingir um dos propósitos da educação escolar. A pergunta inicial, assim, serviu apenas para dar um rumo à nossa discussão e quem sabe inspirar outras, pois, de acordo com Gadamer (2008, p. 489), "para perguntar não pode haver um comportamento potencial, servindo apenas como teste comprobatório, isso porque perguntar não é pôr mas experimentar possibilidades". 
The place of experience in Physical Education Abstract: This paper brings the discussion to the place of experience and knowledge experience as a chance to meet within the body practices in Physical Education. This study is based on Hans-Georg Gadamer's philosophical hermeneutics to understand the movement to legitimize Physical Education in distinct social spaces, placing it in time, contextualizing its tradition and ramifications for knowledge production. Understanding the experience can give us the keys for understanding of the complex phenomenon of human movement, since they cannot be understood as manipulation and control, but as participation and openness.

Keywords: Experience, Physical Education, Hermeneutics

\section{El lugar de la experiencia en el ámbito de la Educación Física \\ Resumen: El presente artículo trae para la discusión} el lugar de la experiencia y del saber de la experiencia cómo posibilidad de conocer en el ámbito de las prácticas corporales en la Educación Física. Para eso, recurre a la hermenéutica filosófica de Hans-Georg Gadamer para comprender el movimiento de la Educación Física en legitimarse en distintos espacios sociales, situándola en el tiempo, contextualizando su tradición y los desdoblamientos de esta para la producción del conocimiento. Comprender la experiencia pode nos posibilitar las claves para la comprensión del fenómeno complejo del movimiento humano, ya que esta no puede ser entendida cómo manipulación y control, mas si cómo participación y apertura.

Palabras clave: Experiencia, Educación Física, Hermenéutica 


\section{REFERÊNCIAS}

BETTI, Mauro. O que a semiótica inspira ao ensino da educação física. Discorpo, São Paulo, n. 3, p. 25-45, 1994.

Por uma teoria da prática. Motus Corporis, Rio de Janeiro, v. 3, n. 2, p. 73-127, 1996.

Educação física como prática científica e prática pedagógica: reflexões à luz da filosofia da ciência. Revista Brasileira de Educação Física e Esporte, São Paulo, v. 19, n. 3, p. 183-197, jul./set. 2005.

BRACHT, Valter. Educação física e aprendizagem social. Porto Alegre: Magister, 1992.

Educação física \& ciência: cenas de um casamento (in)feliz. 2. ed. ljuí: Ed. Unijuí, 2003.

FENSTERSEIFER, Paulo Evaldo. Esporte na contemporaneidade: uma experiência de fronteira In: REZER. R. (Org.) O fenômeno esportivo: ensaios crítico-reflexivos. Chapecó, Argos, 2006, p. 21-31.

FENSTERSEIFER, Paulo Evaldo; GONZÁLEZ, Fernando Jaime. Educação física escolar: a difícil e incontornável relação teoria e prática. Motrivivência, Florianópolis, v. 19, n. 28, p. 27-37, jul. 2007.

FLICKINGER, Hans-Georg. A caminho de uma pedagogia hermenêutica. Campinas, SP: Autores Associados, 2010.

GADAMER, Hans-Georg. O problema da consciência histórica. Tradução Paulo César Duque Estrada. 3. ed. Rio de Janeiro: Editora FGV, 2006.

Verdade e método I: traços fundamentais de uma hermenêutica filosófica. Tradução Flávio Paulo Meurer; revisão da tradução de Enio Paulo Giachini. 10. ed. Petrópolis, RJ: Vozes, 2008.

HERMANN, Nadja. Hermenêutica e educação. Rio de Janeiro: DP\&A, 2002.

HILDEBRANDT-STRAMANN, Reiner. Textos pedagógicos sobre o ensino da educação física. ljuí: Ed. Unijuí, 2001.

KUNZ, Elenor. Transformação didático-pedagógica do esporte. 4. ed. ljuí: Ed. Unijuí, 2000.

Educação Física: ensino e mudanças. 2 ed. ljuí: Unijuí, 2001.

Se-movimentar. In: GONZÁLEZ, F. J.; FENSTERSEIFER, P. E. (Org.). Dicionário crítico de educação física. ljuí: Ed. Unijuí, 2005. 
O lugar da experiência no âmbito...

LARROSA, Jorge. Notas sobre a experiência e o saber da experiência. Revista Brasileira de Educação, São Paulo, n. 19, p. 20-28, jan./abr. 2002.

PALMER, Richard. Hermenêutica. Tradução Maria Luísa Ribeiro Ferreira. Lisboa: Edições 70, 1989.

Endereço para correspondência:

Luciano de Almeida

Instituto Federal de Educação, Ciência e Tecnologia Farroupilha - Campus Santo Augusto

Rua Fábio João Andolhe, 1100 - Bairro Floresta

Santo Augusto/RS - CEP 98.590-000

Recebido em: 20.06.2011

Aprovado em: 13.12.2011

Movimento, Porto Alegre, v. 17, n. 04, p. 247-263, out/dez de 2011. 
